\title{
MAX-DOAS measurements of atmospheric trace gases in Ny-Ålesund - Radiative transfer studies and their application
}

\author{
F. Wittrock, H. Oetjen, A. Richter, S. Fietkau, T. Medeke, A. Rozanov, and J. P. Burrows \\ Institute of Environmental Physics, University of Bremen, Bremen, Germany \\ Received: 20 October 2003 - Published in Atmos. Chem. Phys. Discuss.: 5 December 2003 \\ Revised: 22 June 2004 - Accepted: 23 June 2004 - Published: 28 June 2004
}

\begin{abstract}
A new approach to derive tropospheric concentrations of some atmospheric trace gases from ground-based $\mathrm{UV} / \mathrm{vis}$ measurements is described. The instrument, referred to as the MAX-DOAS, is based on the well-known UV/vis instruments, which use the sunlight scattered in the zenith sky as the light source and the method of Differential Optical Absorption Spectroscopy (DOAS) to derive column amounts of absorbers like ozone and nitrogen dioxide. Substantial enhancements have been applied to this standard setup to use different lines of sight near to the horizon as additional light sources (MAX - multi axis). Results from measurements at $\mathrm{Ny}$-Ålesund $\left(79^{\circ} \mathrm{N}, 12^{\circ} \mathrm{E}\right)$ are presented and interpreted with the full-spherical radiative transfer model SCIATRAN. In particular, measurements of the oxygen dimer $\mathrm{O}_{4}$ which has a known column and vertical distribution in the atmosphere are used to evaluate the sensitivity of the retrieval to parameters such as multiple scattering, solar azimuth, surface albedo and refraction in the atmosphere and also to validate the radiative transfer model. As a first application, measurements of $\mathrm{NO}_{2}$ emissions from a ship lying in $\mathrm{Ny}$-Ålesund harbour are presented. The results of this study demonstrate the feasibility of long term UV/vis multi axis measurement that can be used to derive not only column amounts of different trace gases but also some information on the vertical location of these absorbers.
\end{abstract}

\section{Introduction}

In recent years, ground-based UV/visible measurements of light scattered in the zenith sky have been used to derive atmospheric columns for a number of important atmospheric trace species such as $\mathrm{O}_{3}, \mathrm{NO}_{2}, \mathrm{BrO}, \mathrm{OClO}$, and also $\mathrm{O}_{4}$ (e.g. Noxon, 1975; Noxon et al., 1978; Solomon et al., 1987;

Correspondence to: F. Wittrock

(folkard@iup.physik.uni-bremen.de)
Johnston and McKenzie, 1989; van Roozendael et al., 1994; Richter et al., 1999; Wittrock et al., 2000; Frieß et al., 2001; Tørnkvist et al., 2002). Most of these measurements were focused on stratospheric ozone chemistry in middle and high latitudes, and the DOAS technique in the conventional setup is most sensitive to this altitude region, in particular at low sun. However, technical improvements described in this paper, now also allow monitoring of trace gases mainly located in the troposphere and the distinction of tropospheric and stratospheric column amounts. The main idea is that measurements taken with a telescope pointed towards different elevation angles close to the horizon provide information on the lowest atmospheric layers and in combination with the zenith sky measurement can be used to derive a coarse vertical profile of some absorbers. Observations of the bright horizon ("off-axis") were originally proposed and performed to improve the signal to noise ratio of stratospheric measurements under very low daylight conditions, e.g. twilight observations in polar regions (Sanders et al., 1993; Miller et al., 1997). In contrast to these studies and also related ones using a fixed viewing angle, the system used in this work has the capability to switch between several directions within a short time period to provide quasi simultaneous measurements in different lines of sight. Similar set-ups have also been developed by other groups (Hönninger and Platt, 2002; Bobrowski et al., 2003; Leser et al., 2003; van Roozendael et al., 2003). Here we report on long-term measurements from our instrument installed in Ny-Ålesund, which has been upgraded with a permanent horizon viewing mode in spring 1999.

The ability to properly interpret UV/visible absorption measurements of atmospheric constituents using scattered light depends crucially on how well the optical path of light collected by the system is understood. This knowledge is essential to convert the differential slant columns (DSC - the difference between the column amount of the absorber integrated along the light path through the atmosphere and the absorber amount in the background spectrum), which can 
be derived from the absorption measurements, into a vertical column ( $V C$ - the trace gas concentration integrated along height) with the help of a so-called airmass factor $(\boldsymbol{A} \boldsymbol{M} \boldsymbol{F})$. This factor is defined as the ratio of the effective optical path through the atmosphere to the vertical optical path. In the case of light scattered in the zenith sky, calculations of twilight airmass factors have been made using simple single scattering radiative transfer models (Solomon et al., 1987). Later, several studies have shown that at least for tropospheric absorbers and/or large solar zenith angles (SZAs) multiple scattering has to be taken into account (Perliski and Solomon, 1993). In addition, the full treatment of atmospheric sphericity in the radiative transfer including refraction turned out to be necessary at low sun. As will be shown in this paper, for measurements with the telescope pointed towards the horizon the relative azimuth between observation direction and the sun also plays a role. While simple geometrical considerations or single scattering radiative transfer models as have been used in previous publications (e.g. Hönninger and Platt, 2002) can give a rough estimate of the absorber's concentration, more detailed radiative transfer calculations are needed for quantitative results, in particular for small elevation angles. When analysing horizon measurements of tropospheric species, validation of the results is usually difficult as independent measurements are scarce. Therefore, absorption by the oxygen dimer $\mathrm{O}_{4}$ is used as a test case for sensitivity studies and validation of the measurement technique. The $\mathrm{O}_{4}$ concentration mainly depends on the square of the $\mathrm{O}_{2}$ concentration and thereby pressure and the equilibrium constant which is well known and has only a small dependence on temperature (Perner and Platt, 1980; Greenblatt et al., 1990; Wagner et al., 2002). Thus, from the knowledge of the atmospheric pressure and temperature profile the vertical $\mathrm{O}_{4}$ column can be determined. This calculated column of $\mathrm{O}_{4}$ can be used to determine the correct settings for aerosols and surface albedo in the radiative transfer model by varying these values until agreement with the measurements is found, because the diurnal variation of $\mathrm{O}_{4}$ should be very small. As the $\mathrm{O}_{4}$ absorption cross-section has a number of bands in the UV and visible spectral region, appropriate $\mathrm{O}_{4}$ bands can be found close to most fitting windows used in the DOAS analysis of atmospheric trace species. This is important as for scattered light measurements the effective light path depends on wavelength, and results obtained at long wavelengths (for example from the $\mathrm{O}_{2}$ bands) can not simply be transferred to the UV spectral region. Similar approaches to determining aerosol properties have also been applied for zenith-sky measurements (e.g. Wagner et al., 2002), but as a result of the long tropospheric light path, the sensitivity is much larger when observing the horizon.

\section{Experiment and data analysis}

The MAX-DOAS instrument described in this paper is part of the primary NDSC-station in $\mathrm{Ny}$-Ålesund $\left(78^{\circ} 55^{\prime} \mathrm{N}\right.$, $\left.11^{\circ} 56^{\prime} \mathrm{E}\right)$, Svalbard. Since 1995 ground-based zenith-sky measurements are continuously in operation at this location. After a successful test in April 1998 the first automated MAX-DOAS was set up in 1999. The instrument described below was installed in March 2002 and is typical for the instruments used in the BREDOM network operated by the University of Bremen (BREDOM: Bremian DOAS network for atmospheric measurements).

At Ny-Ålesund ozone sondes are launched at least once a week and weather sondes daily. These provide profiles of temperature, pressure and ozone that can be used as input for the radiative transfer model (see Sect. 3) and for the calculation of the vertical column of $\mathrm{O}_{4}$ (see Sect. 5.1).

\subsection{Experimental setup}

The basic principle of the instrument is that scattered solar light is collected by a telescope from different directions and then transmitted to a spectrograph using a quartz fibre bundle. The spectra are recorded by a detector and saved on a PC that also controls the whole setup. A schematic of the telescope is shown in Fig. 1. The telescope housing is based on a commercial watertight box, where two quartz windows $A$ and $B$ are fitted in for zenith sky measurements and for offaxis observations, respectively. The photo in Fig. 1 illustrates the situation for the off-axis mode: Light from all directions enters through window $\mathrm{B}$. The mirror D only reflects light from a specific angle into the direction of the opening $F$ in the dividing wall. In order to be able to examine light from different angles the mirror is mounted on a revolving table $\mathrm{C}$ driven by a computer controlled motor. For zenith sky measurements the mirror is moved to the left hand side into an upright position to block the light passing through window B while opening the view to the zenith sky port. This is shown in the sketch in Fig. 1. The lens $G$ focuses the light onto the mounting $\mathrm{H}$ for the quartz fibre bundle. The lower part of the telescope housing is designed to perform calibration measurements with a mercury-cadmium lamp $\mathrm{K}$ and a tungsten lamp J, for wavelength calibration and to detect and compensate possible etalon effects, respectively. For that the calibration unit can be separated from the telescope by closing shutter E. The quartz fibre bundle consists of 38 cylindrical single fibres, each of which has a diameter of $150 \mu \mathrm{m}$ (plus $15 \mu \mathrm{m}$ coating). In the telescope, the fibres are positioned discoidal while at the end of the bundle where it is attached to the spectrometer the fibres are arranged in a row to form the slit. In addition to simplifying the set-up of the telescope apart from the spectrometer system, the quartz fibre bundle also has the important function of depolarising the light fed into the spectrometer, thereby minimizing possible artefacts from a polarisation dependency of the instrument. This is 
(a)

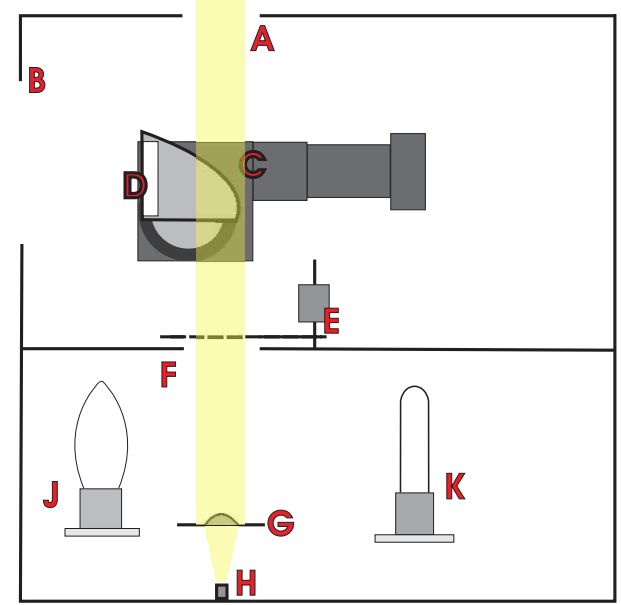

(b)

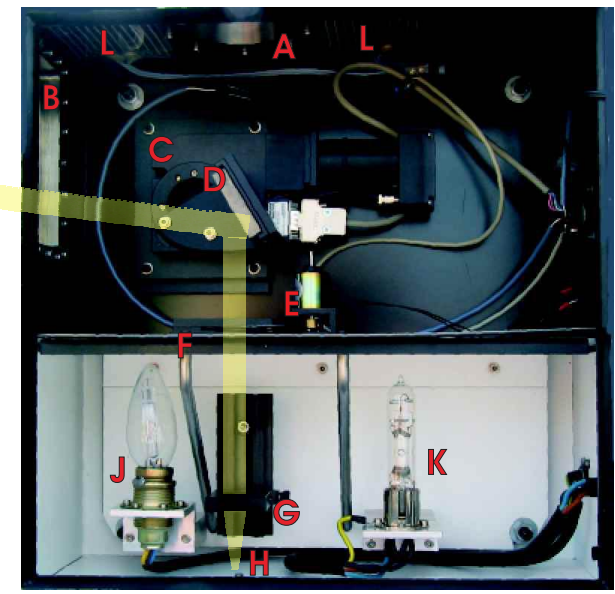

A Zenith window
B Off-Axis-window
C Turntable driven by motor
D Mirror

E Shutter

F Hole in dividing wall

G Lens

H Quartz fibre bundle

Jungsten lamp

K HgCd lamp

$\mathbf{L} \quad$ Heating foil

Fig. 1. Illustration of the MAX-DOAS entrance optic. The scheme on the left shows the position of the mirror for zenith sky observations, whereas the photo on the right was taken in the horizon viewing mode.

of particular importance as the mirror used in the telescope introduces an additional polarisation. As a spectrometer, an Oriel MS 257 (Oriel, 2001) is used. This spectrometer is of the imaging asymmetric Czerny-Turner type and has an exit focal length of $257.36 \mathrm{~mm}$. The entrance slit is enlarged by a factor of 1.6 in the vertical and 1.1 in the horizontal. The spectrometer is equipped with an automatic grating turret having in our setup two gratings, one with 1200 lines $/ \mathrm{mm}$ and another with 600 lines $/ \mathrm{mm}$. In order to obtain good spectral stability of the system, the spectrometer is insulated and thermally stabilized to within $0.1 \mathrm{~K}$. The detector used is a CCD (Charge-Coupled Device) of the DV 440-BU type provided by Andor Technology (Oriel, 2001). The chip has a resolution of $2048 \times 512$ pixels and is cooled to $-40^{\circ} \mathrm{C}$, to reduce dark current and the impact of hot pixels. Each pixel has a size of $13.5 \times 13.5 \mu \mathrm{m}^{2}$. In order to have a better sensitivity in the ultraviolet spectrum the chip is thinned and back-illuminated. With this set-up, a spectral resolution of $0.5 \mathrm{~nm}$ and an oversampling of 11 is obtained for the grating with $12001 / \mathrm{mm}$. This is derived from the FWHM of a representative line in the spectrum of the Mercury-Cadmium lamp. Continuous measurements with this setup are performed since 1 March 2002 in the wavelength region from $325 \mathrm{~nm}$ to $413 \mathrm{~nm}$. A PC sets the configuration of the system and controls the automatic measurements. One zenith sky and horizon measurements in four directions are usually executed in a row. In the years 1998 to 2001 a slightly modified setup was used where a cooled Reticon photodiode array served as the detector. Furthermore there was only one offaxis direction possible which was chosen to be $4^{\circ}$ above the horizon.

\subsection{Data analysis}

The spectra measured with the above described setup are analysed using the well known DOAS method (Platt, 1994). In this technique, only the narrowband, i.e. the differential structures of the absorption cross-sections are used to identify absorbers and quantify their integrated amount along the light path. Broadband absorption and extinction by Mie and Rayleigh scattering and broadband instrumental features are removed by a polynomial of low order. This polynomial as well as the differential absorption cross-sections of all relevant absorbers together with a reference spectrum usually taken at high sun are fitted to the logarithm of the measured spectra. To account for the effects of Raman scattering in the atmosphere, a pseudo cross-section was created with the SCIATRAN model (Vountas et al., 2001) which is treated as an additional absorber (Ring) in the analysis. The DOAS fit algorithm yields the so-called differential slant column $(\boldsymbol{D S C})$ which represents the excess absorption - with respect to the absorption in the reference spectrum - along the light path. For the $\mathrm{O}_{2}-\mathrm{O}_{2}$ dimer a spectral fitting window from 354 to $387 \mathrm{~nm}$ was chosen which includes two of the three strong absorption lines in the wavelength region covered by the instrument. In this window ozone is a weak absorber. Only $\mathrm{NO}_{2}, \mathrm{BrO}$ and a synthetic Ring cross-section as well as the noon spectrum of the respective day together with a polynomial of third order were fitted to the measured spectrum. An example of an $\mathrm{O}_{4}$ fit is shown in Fig. 2. 


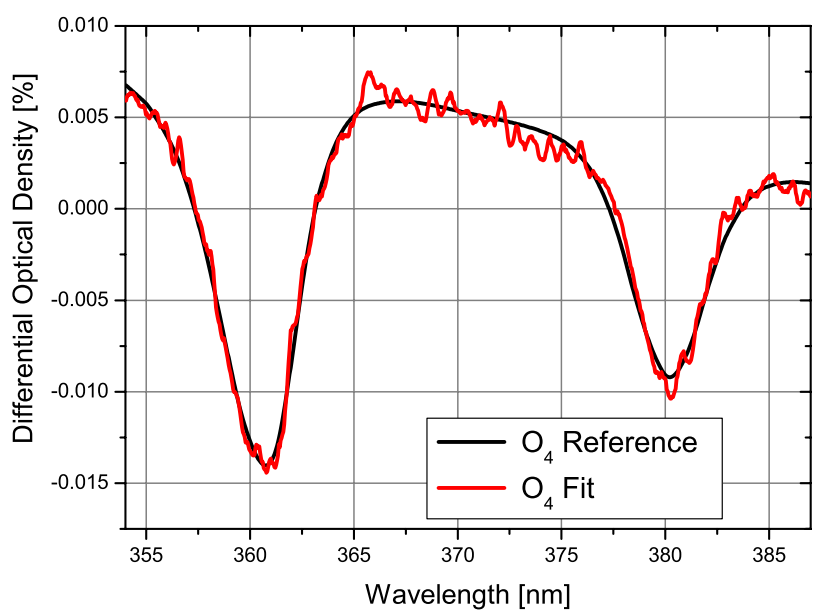

Fig. 2. Example of an $\mathrm{O}_{4}$ fit for an elevation angle of $3^{\circ}$ on 26 April 2003. The black solid line is the scaled laboratory reference, the red line the fit result. This fit yields an $\mathrm{O}_{4} \boldsymbol{D S C}$ of $5.16 \times 10^{43} \mathrm{molec}^{2} \mathrm{~cm}^{-5}$ having a linear fit error of $0.5 \%$. As background for this fit a zenith sky noon spectrum was used. A polynomial of degree $3, \mathrm{NO}_{2}, \mathrm{BrO}$ and a modeled Ring spectrum have been included.

\subsection{MAX-DOAS and geometry}

Among other things the slant column of an absorber depends on the position of the sun. Two angles describe the movement of the sun relative to the telescope during the day: the solar zenith angle (SZA) and the relative azimuth which is the azimuth angle between the direction of the telescope and the direction of the sun. For zenith sky measurements the relative azimuth is irrelevant. However, for off-axis directions the relative azimuth has to be taken into consideration which will be shown below. The elevation angle indicates the pointing of the telescope and is defined by the angle between the tangential plane of the earth's surface and the direction of the telescope. Thus an elevation angle of $90^{\circ}$ denotes zenith sky.

By means of the slant column's diurnal cycle it can be determined if a gas mainly absorbs in the troposphere or in the stratosphere. For zenith sky measurements a simple model that only takes single scattering of the light into account is able to illustrate the basic mechanisms: For large SZA the photons cover a long and slant distance from the sun to the upper atmosphere before getting scattered in the zenith into the telescope. The most likely scattering height depends on the solar zenith angle and displaces rapidly upward with the sinking sun. For a stratospheric absorber the slant column increases with increasing SZA as long as the scattering height lies initially below and than within the absorbing layer. If at very low sun the most likely scattering height is situated above the absorbing layer the slant column decreases in turn. A tropospheric trace gas absorbs below the most likely scattering height along a relatively short light path which changes only slightly with the solar zenith angle. This model is a

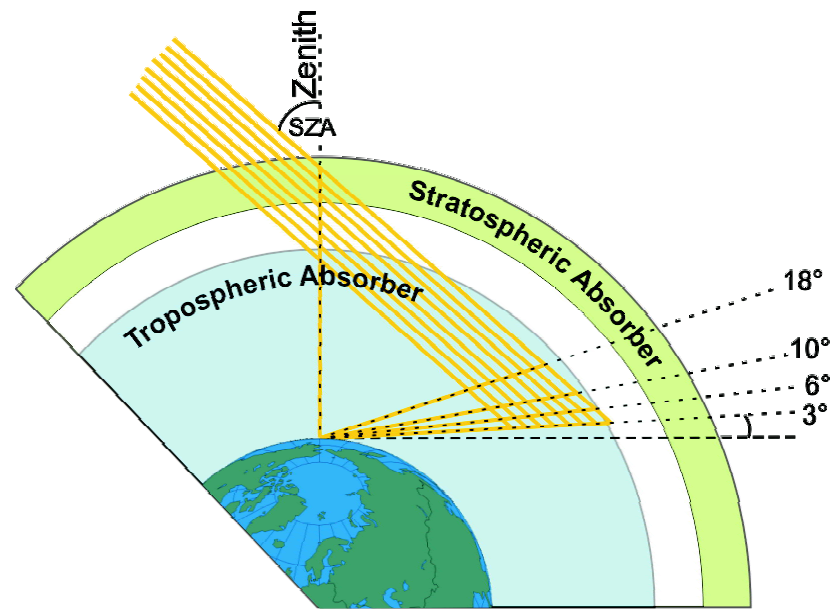

Fig. 3. Illustration of the MAX-DOAS geometry. Horizon viewing observations have a similar path through the stratosphere, whereas the light path in the troposphere is extended and increases with decreasing elevation angle.

good approximation for stratospheric absorbers. In the troposphere multiple scattering gains in importance. Additional information on the vertical profile can be obtained by horizon viewing directions. The light path for this geometry is enhanced in the lower atmosphere compared to zenith sky measurements (see Fig. 3). In the measurements described here, the four off-axis directions are chosen to lay particular emphasis on absorption in the troposphere. They comprise the elevation angles $3^{\circ}, 6^{\circ}, 10^{\circ}$ and $18^{\circ}$. In this case the photon path is affected by multiple scattering effects which necessitate comparison of the measured slant columns with model calculations in order to gain vertical columns and profile information of the absorbers. An illustration of the sensitivity the different viewing modes have for absorbers located in different altitudes is given in Fig. 4. While the zenith sky direction has a low sensitivity to the lower atmosphere, the $18^{\circ}$ direction is already more sensitive to the troposphere in general and the lower viewing directions have increasing sensitivity to the boundary layer.

\section{Radiative transfer modelling}

The output of the DOAS analysis are usually differential slant columns ( $\boldsymbol{D S C})$. To convert these into vertical columns $(V C)$ which are independent of the viewing geometry, airmass factors $(\boldsymbol{A} \boldsymbol{M} \boldsymbol{F}$ s $)$ have to be calculated with a radiative transfer model. The $\boldsymbol{A M F}$ describes the weighting of the absorption as a function of solar zenith angle and relative azimuth as well as the wavelength of the radiation and is defined by the ratio of the slant column $(\boldsymbol{S C})$ to the vertical column $(V C)$ :

$A M F=S C / V C$ 


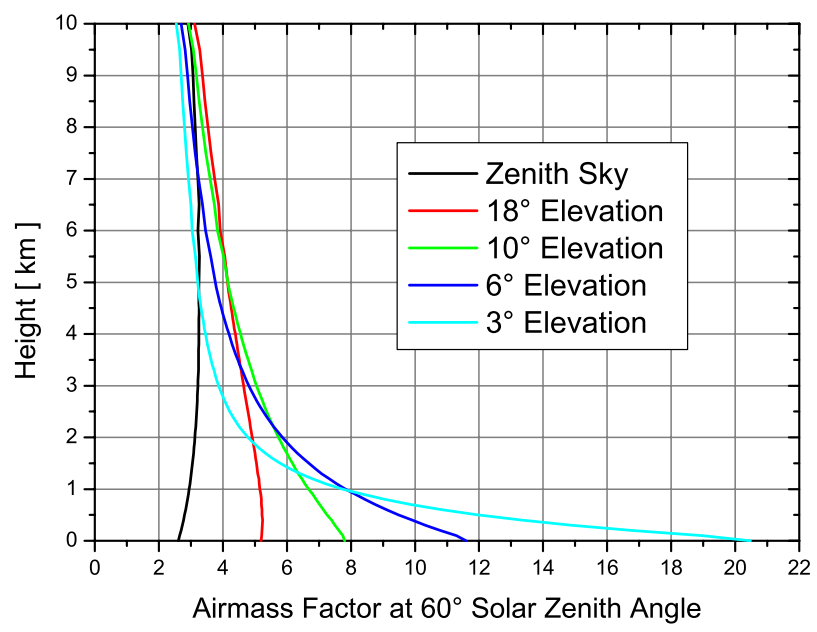

Fig. 4. Height dependence of the sensitivity for the different viewing directions at $60^{\circ} \mathrm{SZA}$. The value on the $\mathrm{x}$-axis is the airmass factor for a thin layer positioned in the height given on the $y$-axis. The large $\boldsymbol{A M F}$ for the $3^{\circ}$ elevation viewing direction in the lowest layers indicates a large sensitivity to absorbers located close to the ground.

where $\boldsymbol{S C}$ is the sum of the $\boldsymbol{D S C}$ and the $\boldsymbol{S C _ { 0 }}$ in the background spectrum. Thus the diurnal cycle of the $\boldsymbol{A M F}$ follows that of the slant column unless the total amount or vertical profile of the absorber changes in the course of the day.

\subsection{The model SCIATRAN}

Within this work the radiative transfer model SCIATRAN (Rozanov et al., 2000) (CDIPI-version: combined differential-integral approach involving the Picard iterative approximation) was used to calculate the airmass factors. In this model the full spherical radiative transfer equation is converted into an integral form by using the characteristic method. This integral form is solved in an iteration scheme for the intensity. As initial estimate for the diffuse radiation field the output of a pseudo-spherical approach to the radiative transfer equation is used. The interested reader can find a detailed description of the model SCIATRAN together with all relevant equation elsewhere (Rozanov et al., 2000, 2001). In order to calculate airmass factors SCIATRAN is conducting two runs for the radiance $I$ : One with the selected absorber $\left(\boldsymbol{I}_{+j}\right)$ and one without $\left(\boldsymbol{I}_{-j}\right)$. Then the $\boldsymbol{A} \boldsymbol{M} \boldsymbol{F}$ is obtained by:

$\boldsymbol{A M \boldsymbol { F } _ { j }}(\lambda)=\frac{\ln \left(\boldsymbol{I}_{+j}(\lambda) / \boldsymbol{I}_{-j}(\lambda)\right)}{\boldsymbol{V O O} \boldsymbol{D}_{j}(\lambda)}$

where $\boldsymbol{V} \boldsymbol{O} \boldsymbol{D}_{j}$ is the vertical optical depth of the whole atmosphere for the absorber $j$ and $\lambda$ is the wavelength. This approach was first published by (Perliski and Solomon, 1993) and assumes an optically thin atmosphere, a condition that usually is fulfilled in the measurements presented here.

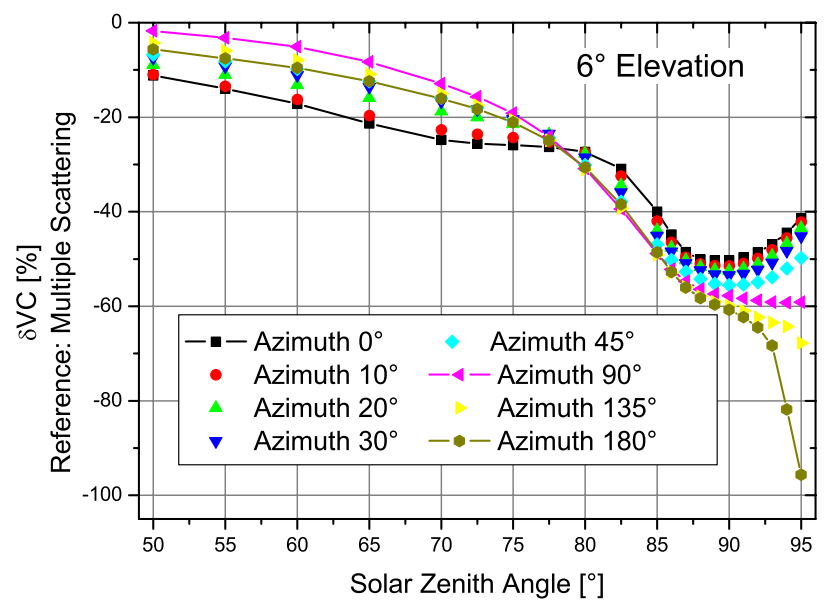

Fig. 5. Effect of neglecting multiple scattering on the calculated vertical column of $\mathrm{O}_{4}$. For an elevation angle of $6^{\circ}$ the vertical column will be underestimated, if only single scattering is taken into account for the airmass factor.

\section{Sensitivity studies for $\mathrm{O}_{4}$}

When modelling the radiative transfer in the atmosphere, a number of parameters has to be set to realistic values. The most important ones are the viewing geometry, the position of the sun, wavelength, and the vertical profiles of absorbers, pressure and temperature. However, surface albedo and the atmospheric aerosol loading also have an impact on the results. For simplicity, all calculations in this work were made without consideration of clouds.

In Ny-Ålesund at least weekly profiles for the absorber ozone and daily temperature and pressure profiles of the atmosphere are available through ozone soundings and radiosondes, respectively. Above the burst height of the balloon the profiles are completed with values from a model climatology provided by the MPI (Brühl and Crutzen, personal communication ${ }^{1}$ ). These profiles are used as realistic meteorological input for the model calculations.

In the following sections, the influence of multiple scattering, the relative azimuth, surface albedo, aerosols and the refraction on the $\mathrm{O}_{4} \boldsymbol{A} \boldsymbol{M} \boldsymbol{F}$ and consequently the calculated vertical column are investigated with model data. Such sensitivity studies are necessary to determine which parameters need to be known to which accuracy to derive realistic vertical columns from the measurements. The results are presented in the form of a ratio between a reference airmass factor $\boldsymbol{A} \boldsymbol{M} \boldsymbol{F}^{\mathrm{Ref}}$ of a standard scenario with the airmass factor $\boldsymbol{A} \boldsymbol{M} \boldsymbol{F}$ ' obtained with one of the above mentioned parameters changed. This ratio indicates the error in the vertical column that is introduced when setting the respective parameter to an inappropriate value (Figs. 5, 8, 9, 12, 13). Whenever

\footnotetext{
${ }^{1}$ Brühl, C. and Crutzen, P.: Chemo-dynamical model of the stratosphere: profile data base, personal communication, 1993.
} 


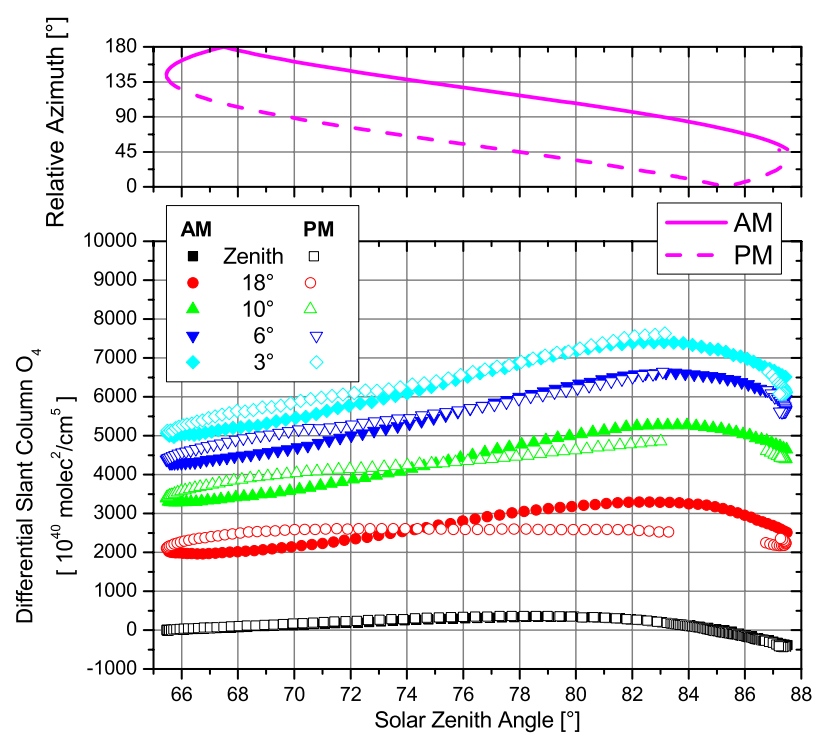

Fig. 6. Diurnal variation of the measured $\mathrm{O}_{4} \boldsymbol{D S C}$ s on 26 April 2003. As background the zenith sky noon spectrum from the same day was used. On this very clear day (only thin clouds in the late evening) the azimuthal dependency of the measured $\mathrm{O}_{4}$ is clear.

more information is necessary to illustrate the influence of one parameter, additional figures are shown.

For the reference $\boldsymbol{A M} \boldsymbol{F}$, the atmospheric profile from 3 April 2002 was used and a Fraunhofer reference spectrum taken at $60^{\circ} \mathrm{SZA}$ in the zenith direction was assumed. All calculations shown have been done for $370 \mathrm{~nm}$ (the center of the $\mathrm{O}_{4}$ fitting window), an albedo of 0.5 , a background arctic aerosol (see Fig. 11; Herber, A., personal communication, 2000.) and full multiple scattering and refraction.

It is important to note, that the sensitivity studies are presented in the form in which the $\boldsymbol{A M F}$ will be applied to the actual measurement. Therefore, not the absolute $\boldsymbol{A M F}$ but rather the difference in $\boldsymbol{A} \boldsymbol{M} \boldsymbol{F}$ between a horizon measurement and the background zenith measurement at $60^{\circ} \mathrm{SZA}$ is used for the comparison with the reference scenario. This relative quantity sometimes has a larger sensitivity to changes in model parameters than the absolute $\boldsymbol{A} \boldsymbol{M} \boldsymbol{F}$ s, but as it reproduces the real measurement situation, it seems the appropriate choice.

\subsection{Multiple scattering}

For a qualitative interpretation of MAX-DOAS measurements, simple geometric considerations have sometimes been used to estimate the airmass factors (see Sect. 2.3). However, in the troposphere multiple scattering at least for the used wavelength region cannot be ignored, and using a single scattering approximation introduces large errors. This is illustrated in Fig. 5, where for an elevation angle of $6^{\circ}$ the underestimation of the vertical column increases from a few

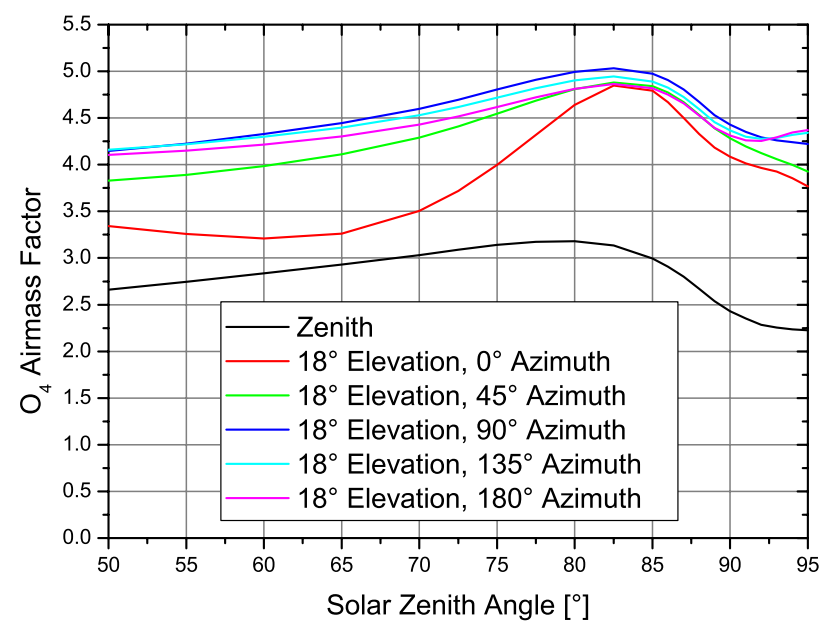

Fig. 7. Absolute airmass factors for $\mathrm{O}_{4}$. Pointing the instrument towards the sun $\left(0^{\circ}\right.$ relative azimuth) leads to decreasing differences between horizon and zenith sky $\boldsymbol{A} \boldsymbol{M} \boldsymbol{F}$.

percent at high sun to more than $50 \%$ at low sun depending on the relative azimuth. As is to be expected, the influence of multiple scattering increases with decreasing elevation angle (not shown). The reason for the large impact of multiple scattering is twofold: on one hand, the airmass factor for the zenith sky measurement increases with multiple scattering, thereby decreasing the difference between horizon and zenith measurement. On the other hand, the airmass factor for the horizon viewing mode is slightly increased by multiple scattering for high sun, but clearly decreased at low sun. The combination of both effects results in the behaviour shown in Fig. 5.

\subsection{Relative azimuth}

When analysing the $\mathrm{O}_{4}$ columns measured under different elevation angles on a clear day, it is apparent that the values do not only depend on solar zenith angle as in the case of zenith sky measurements, but also vary with the relative azimuth angle. This becomes apparent from Fig. 6, which shows measurements of $\boldsymbol{D S C}$ from 26 April 2003. As the instrument is pointed towards the $\mathrm{NNW}$, the relative azimuth varies over the day, and morning and afternoon measurements taken at the same SZA differ significantly.

In order to evaluate the impact of the relative azimuth between measurement direction and the sun, airmass factors have been calculated for different elevation angles $\left(3^{\circ}, 10^{\circ}\right.$ and $18^{\circ}$ ) and then sorted according to the relative azimuth. The main effect is, that the $\boldsymbol{A} \boldsymbol{M} \boldsymbol{F}$ is significantly smaller when looking towards the sun, in particular for higher elevation angles (see Fig. 7). This is a result of the strong forward peak in Mie scattering, that reduces the effective light path in this geometry (van de Hulst, 1981). The effect on the difference between the horizon $\boldsymbol{A} \boldsymbol{M} \boldsymbol{F}$ and the zenith $\boldsymbol{A} \boldsymbol{M} \boldsymbol{F}$ can be 


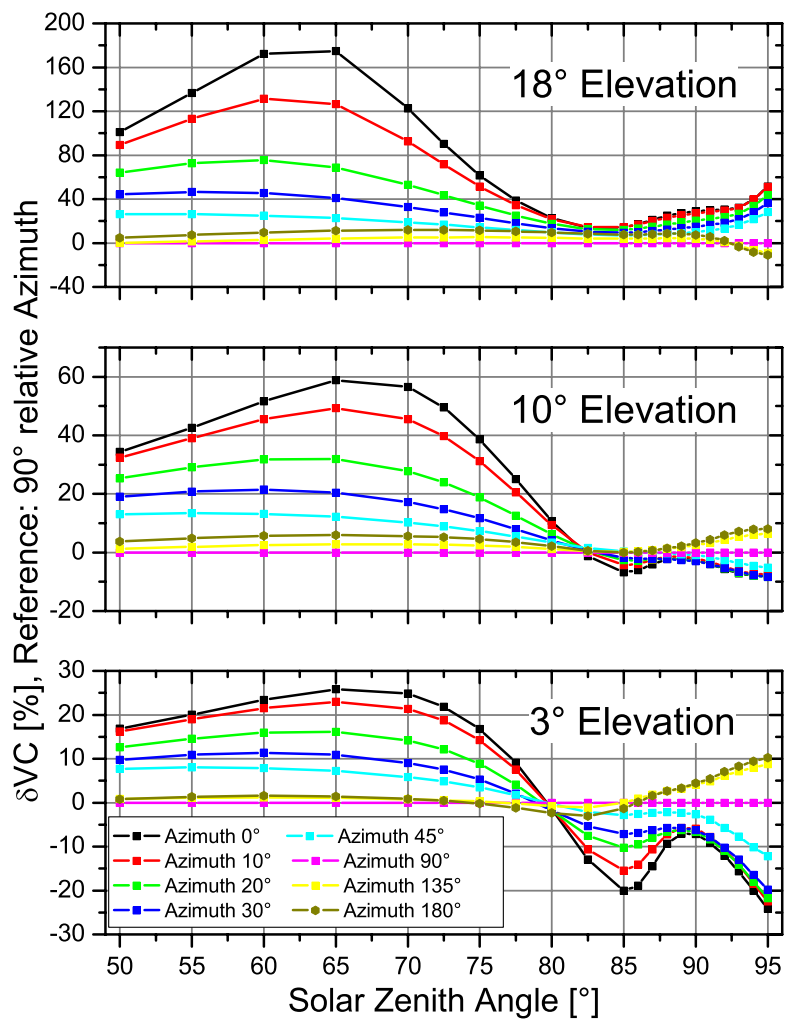

Fig. 8. Effect of the relative azimuth angle on the calculated $V C$. Shown is the error introduced in the vertical column of $\mathrm{O}_{4}$ if an azimuth angle different from the $90^{\circ}$ of the reference case is used in the airmass factor calculation.

quite large as shown in Fig. 8. Here, the error of the vertical columns is shown that is introduced when using a deviating azimuth instead of the correct relative azimuth of $90^{\circ}$ in the $\boldsymbol{A} \boldsymbol{M} \boldsymbol{F}$ calculations. The azimuth effect is relevant for all elevation angles, and is largest for higher elevations and a small relative azimuth. For all azimuth angles pointing away from the sun the error is smaller than $10 \%$ for SZAs less than $93^{\circ}$.

From the results of this test we conclude, that it is preferable to point a horizon viewing instrument away from the sun (This is not practicable at high latitudes!), and that the correct azimuth has to be taken into account in the $\boldsymbol{A M F}$ calculation.

\subsection{Albedo}

Surface albedo changes have a significant impact on the intensity of the diffuse radiation field close to the surface. In $\mathrm{Ny}$-Ålesund, very different albedo values can be found depending on season and viewing direction, for example when comparing snow covered ground and open water. To study the impact of albedo on the $\boldsymbol{A} \boldsymbol{M} \boldsymbol{F}$, calculations with the albedo of freshly fallen snow (0.9) and a very small albedo (0.01) are compared to a medium albedo of 0.5 . For the lowest elevation angle $\left(3^{\circ}\right)$ the vertical column will be underesti-

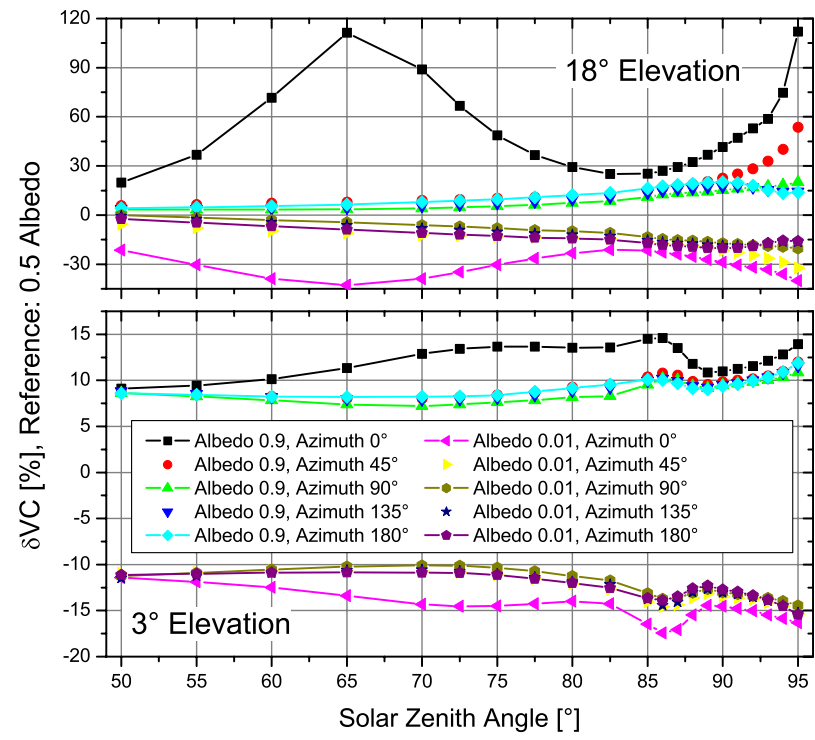

Fig. 9. Effect of the albedo on the calculated $V C$. Shown is the deviation introduced in the vertical column of $\mathrm{O}_{4}$ if an albedo different from 0.5 of the reference is used in the airmass factor calculation.

mated when a too small albedo is assumed and overestimated when the albedo is too high (Fig. 9). At an elevation of $18^{\circ}$ the same trend can be observed for the directions pointing away from the sun. However, for the direction towards the sun, i.e. $0^{\circ}$ azimuth, using a wrong albedo has a big impact on the vertical column (see the Sect. 4.2). For relative azimuths larger than $45^{\circ}$, the error introduced by using an inappropriate albedo is generally less than $20 \%$.

Figure 10 shows the relative $\boldsymbol{A} \boldsymbol{M} \boldsymbol{F}$, i.e. the difference between the actual $\boldsymbol{A} \boldsymbol{M} \boldsymbol{F}$ and the $\boldsymbol{A} \boldsymbol{M} \boldsymbol{F}$ of midday at $60^{\circ}$ SZA. As can be seen, the difference is decreasing with increasing albedo. This results in a higher relative sensitivity of the off-axis measurements for a small albedo which at first glance is surprising. The reason for this unexpected behaviour is not so much the effect of high albedo on the low elevation measurements but an increased sensitivity of the zenith-sky viewing direction. For high albedo the number of photons scattered close to the ground is larger, making the zenith-sky measurements more sensitive to absorption in the troposphere. This reduces the difference in $\boldsymbol{A} \boldsymbol{M F}$ between horizon and zenith-sky viewing directions.

In summary, the impact of albedo changes on the $\boldsymbol{A M F}$ is significant, in particular when looking towards the sun. Good albedo estimates are needed for the analysis (or have to be derived from the measurements themselves) and again it is simplifying the analysis if the telescope is pointed away from the sun.

\subsection{Aerosols}

The optical properties of aerosols are determined by their composition, their shape and relative humidity. For the 


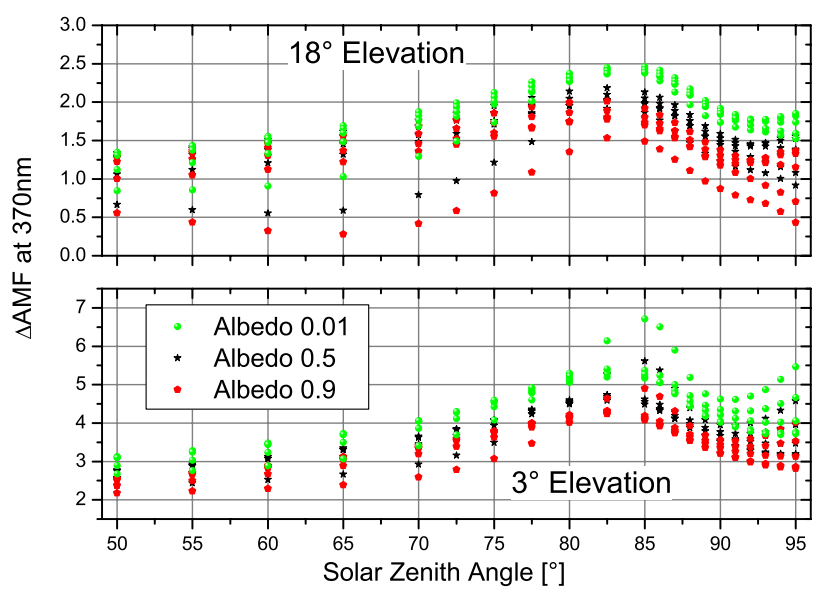

Fig. 10. Differences of $\boldsymbol{A} \boldsymbol{M} \boldsymbol{F}$ for $\mathrm{O}_{4}$ calculated with different albedos. All relative azimuth angles from previous figures are plotted but for clearness not with extra symbols indicated. All $\boldsymbol{A M F}$ are related to the zenith sky $\boldsymbol{A} \boldsymbol{M} \boldsymbol{F}$ calculated at $60^{\circ}$ solar zenith angle. Although absolute $\boldsymbol{A M} \boldsymbol{F}$ are getting larger for increasing albedo, the inverse behaviour is true for $\boldsymbol{A} \boldsymbol{M} \boldsymbol{F}$ differences between off-axis and zenith sky.

impact on the $\boldsymbol{A M F}$, the vertical distribution of the aerosols also plays an important role. In general, increasing the aerosol extinction reduces the light path for the lower viewing directions but has little impact on the zenith directions, thereby reducing the difference in tropospheric absorption path for the different viewing directions. For the sensitivity studies, a simplified vertical extinction profile - based on measurements in Svalbard during the ASTAR-Campaign 2000 (Herber, A., personal communication, 2000) - was used. In the troposphere, a marine aerosol type was chosen, aged volcanic aerosol for the stratosphere and above that meteor dust. The standard extinction coefficient is shown in Fig. 11. The relative humidity was set to $50 \%$ in the lowermost $5 \mathrm{~km}$ of the atmosphere.

In this study, only the total extinction was changed: The background scenario is compared with very strong extinction as would be observed in an arctic haze event (Herber, A., personal communication, 2000) and with no aerosols at all, i.e. zero extinction coefficient throughout the whole atmosphere. The results are shown in Fig. 12 for three elevation angles. For the lowest elevation, the light path increases with decreasing extinction, and using a high aerosol scenario instead of the standard scenario will lead to a $10 \%$ overestimation of $\mathrm{O}_{4}$. Similarly, using a Rayleigh atmosphere in the airmass factor calculations will lead to a $10-20 \%$ underestimation of the real column. For higher elevations, the sensitivity to aerosols decreases, but azimuth effects are more important. In particular, the $0^{\circ}$ azimuth direction (pointed towards the sun) is very sensitive to changes in the aerosol extinction, mainly because the airmass factor for this direction is very close to the one of the zenith sky background measurement (see Fig. 7).

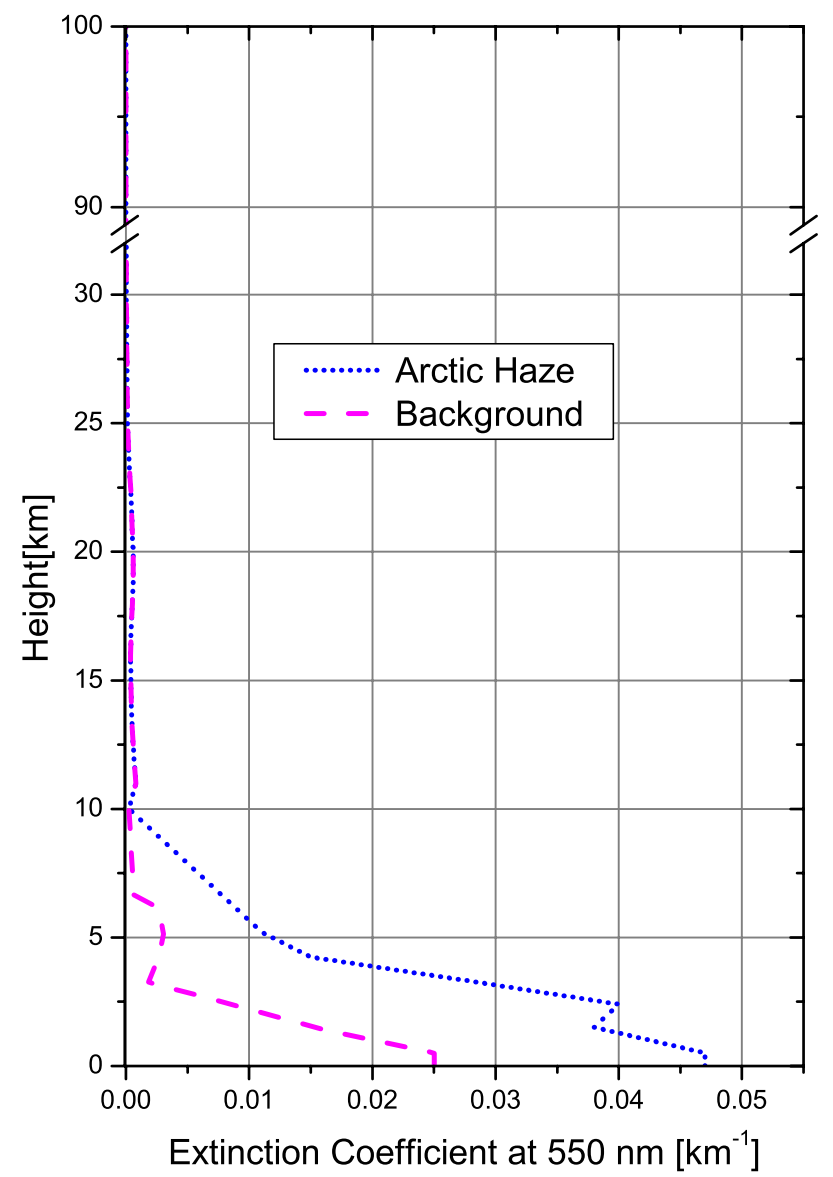

Fig. 11. Profiles of the aerosol extinction coefficient at $550 \mathrm{~nm}$ used for $\boldsymbol{A M F}$ calculations shown in Fig. 12.

\subsection{Refraction}

As a result of refraction in the atmosphere, the solar disc can be seen during dusk and dawn for some time even when it is geometrically below the horizon. In the SCIATRAN model, including refraction in the horizon viewing geometry is computationally expensive, and therefore the effect of neglecting refraction on the $\boldsymbol{A M F}$ was evaluated. As can be seen in Fig. 13, the error in the vertical would be well below $1 \%$ at SZAs smaller than $80^{\circ}$ depending on viewing geometry (elevation and azimuth) and increases for larger SZA. Thus, in most cases refraction is of minor importance.

\subsection{Summary of the model studies}

The results of the model studies for $\mathrm{O}_{4}$ show, that multiple scattering can not be ignored, whereas refraction has only a minor impact on the results. The relative azimuth between sun and viewing direction has a significant effect and has always to be taken into account, in particular when the instrument is not pointed away from the sun and/or for measurements at high latitudes. The effect is much more pronounced 


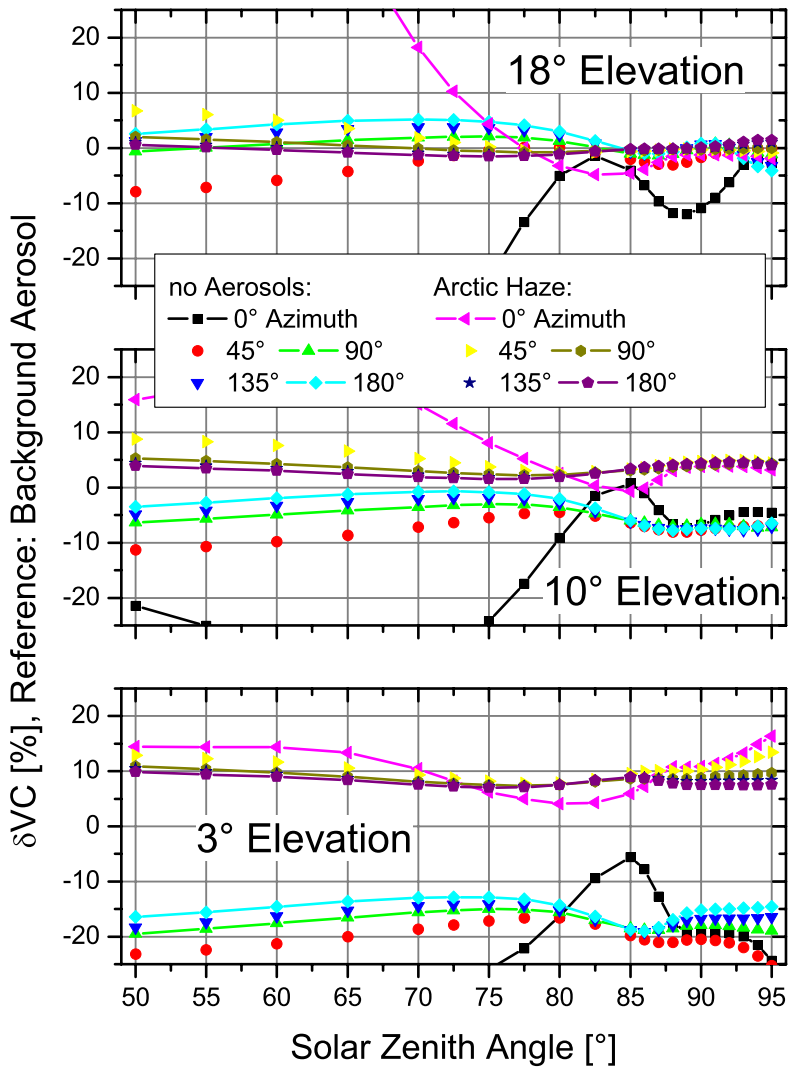

Fig. 12. Effect of the aerosol extinction profile on the calculated $V C$. Shown is the error introduced in the vertical column of $\mathrm{O}_{4}$ if aerosol scenarios different from the background aerosol of the reference are used in the airmass factor calculation.

when the realistic case of a zenith sky background spectrum with non negligible $\mathrm{O}_{4}$ content is considered. Both, aerosol extinction and surface albedo can have a large effect on the airmass factors, and determining these parameters is crucial for a quantitative retrieval. The albedo can be adequately determined through weather observation or Web Cam pictures whereas the aerosol scenario persists to be an element of uncertainty. However, the measurements from different lines of sight can be used to get aerosol information as is shown in (Heckel et. al., 2004). In all sensitivity studies, only one parameter was changed at a time to simplify interpretation. However, some of the parameters are clearly not independent from each other, and for example the effect of surface albedo might vary with aerosol extinction. Also, absorbers with a different vertical profile will not behave exactly as $\mathrm{O}_{4}$ does, in particular if they are confined to the boundary layer. However, the qualitative behaviour will be the same, and $\mathrm{O}_{4}$ has the advantage of providing the opportunity to validate the model results.

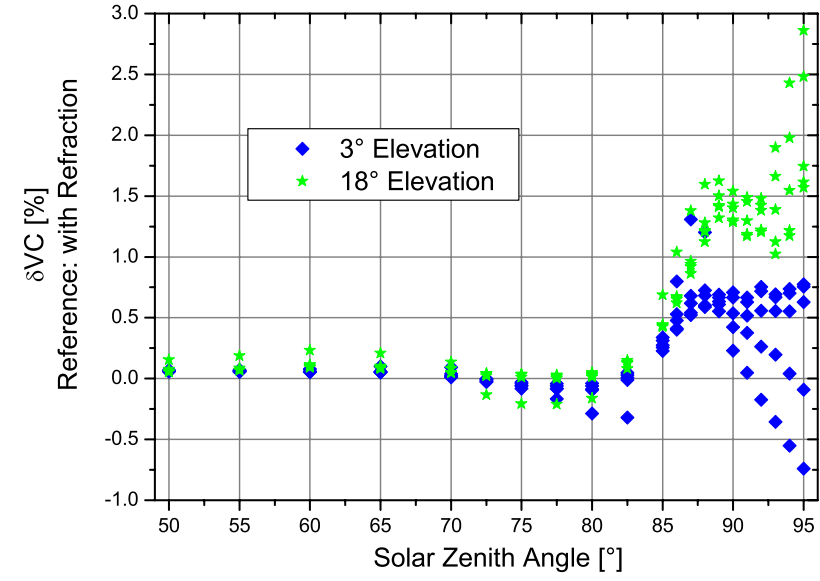

Fig. 13. Effect of neglecting refraction on the calculated $V C$. Only for solar zenith angles larger than $85^{\circ}$ the introduced errors are larger than $0.5 \%$.

\section{Measurement results}

An important test of the quality of the radiative transfer model used is comparison of modeled and measured $\mathrm{O}_{4}$ vertical columns. In this section, vertical columns of $\mathrm{O}_{4}$ on two selected days in 2002 and 2003 are shown, when weather conditions were stable and few clouds occured. Actual meteorological profiles and albedo settings have been used for the radiative transfer calculation. Starting with realistic aerosol scenarios (see Sect. 4.4) the extinction profile and the composition of the different aerosol layers have been changed until closure of vertical columns of $\mathrm{O}_{4}$ for all lines of sight has been reached.

\section{$5.1 \mathrm{O}_{4}$}

In Fig. 14, $\mathrm{O}_{4}$ vertical columns are shown for 26 April 2003 and 13 July 2002. The first day was selected as it was exceptionally clear at least before 20:00 UT, the second as the $\mathrm{NO}_{2}$ columns measured on that day show an interesting feature discussed in the next section.

When judging the quality of the $\mathrm{O}_{4}$ vertical columns, three criteria have to be examined: a) how well the different viewing directions agree in the vertical column, b) how constant the derived vertical column is over the day, and c) how well the measured vertical column agrees with the value derived from the independent sonde measurement.

Overall the agreement between the vertical columns obtained from the different viewing directions is excellent on both days. The small scatter in the data from 13 July 2002 is related to very thin clouds that were sometimes observed on that day. The good agreement indicates, that the SCIATRAN model is capable of simulating the different light paths through the atmosphere with high accuracy. 

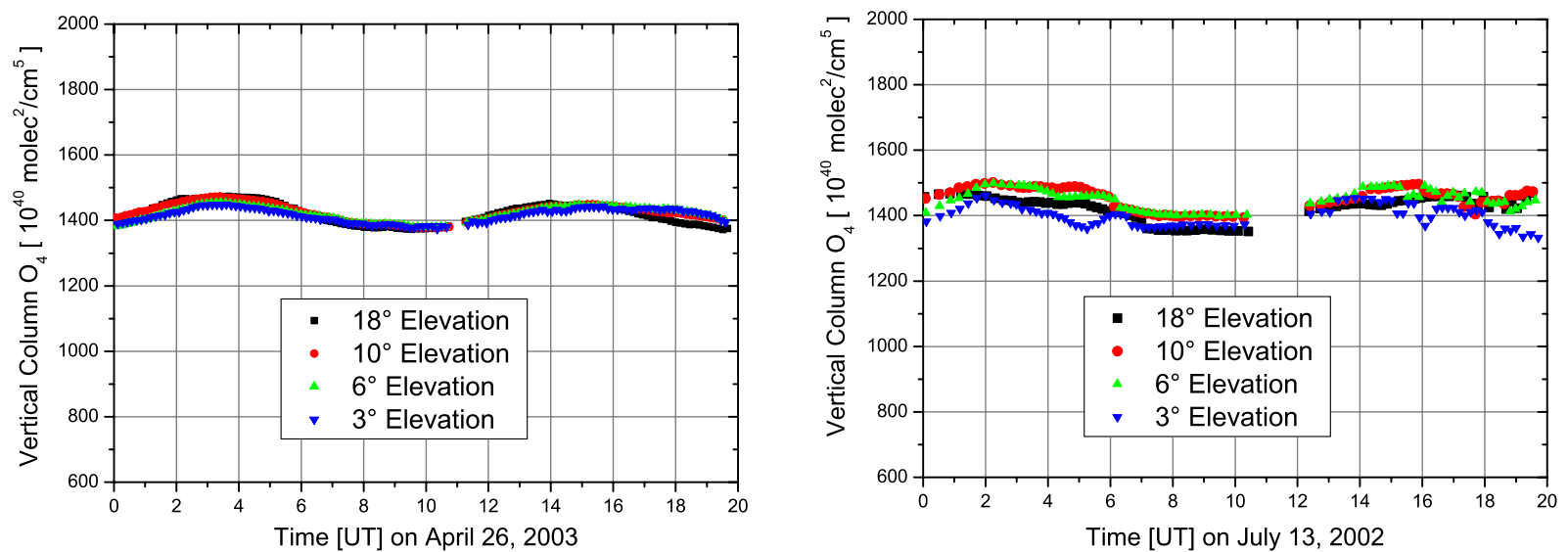

Fig. 14. Vertical columns of $\mathrm{O}_{4}$ calculated for all off-axis directions from slant columns measured on two selected days. See text for a detailed description.

When looking at the variation of the retrieved $\mathrm{O}_{4}$ vertical column over the day, a systematic pattern is apparent in the April measurements. This pattern with an amplitude of roughly $1 \times 10^{42} \mathrm{molec}^{2} \mathrm{~cm}^{-5}$ is observed on some but not all days. It is related to the relative azimuth and probably indicates a mismatch between the aerosol phase function used in the model and the real value. However, the absolute variation is small (7\% peak to peak) and does not have a big impact on the accuracy of the analysis.

The derived $\mathrm{O}_{4}$ columns were also compared to the columns derived from sonde measurements. The latter yield $1.50 \times 10^{43} \mathrm{molec}^{2} \mathrm{~cm}^{-5}$ on 23 April 2003, $1.44 \times 10^{43} \mathrm{molec}^{2} \mathrm{~cm}^{-5}$ on 30 April 2003 and $1.38 \times 10^{43} \mathrm{molec}^{2} \mathrm{~cm}^{-5}$ on 13 July 2002 . As the temporal match is not perfect for April 2003, no direct comparison is possible. However, the derived value of $1.44 \times 10^{43}$ molec $^{2} \mathrm{~cm}^{-5}$ is close to the numbers measured before and after by the sonde. The same is true for the second measurement, that agrees with the sonde within $4 \%$.

In summary, the results of the comparison between the retrieved $\mathrm{O}_{4}$ vertical columns and the independent measurements is very favourable, and lends confidence to the model performance and the retrieval approach.

\section{$5.2 \quad \mathrm{NO}_{2}$ case study}

To demonstrate the application of multi axis measurements to tropospheric pollution studies, measurements from 13 July 2002 were analysed for $\mathrm{NO}_{2}$. Usually, $\mathrm{Ny}$-Ålesund is a clean air site with little $\mathrm{NO}_{2}$ in the boundary layer, and only emissions by the local power generator can lead to occasional $\mathrm{NO}_{2}$ peaks if the exhaust plume moves into the field of view of the instrument. However, in summer cruising ships frequently visit the harbour of $\mathrm{Ny}$-Ålesund, and their emissions can be observed in the measurements as the instrument is pointed towards the fiord. This is of interest as model studies predict a significant impact of $\mathrm{NO}_{\mathrm{x}}$ emissions from ships on the global tropospheric $\mathrm{NO}_{\mathrm{x}}$ budget (Lawrence and Crutzen, 1999), but up to now there has been no experimental verification. In principle, automated MAX-DOAS observation could provide this type of missing evidence.

On 13 July (a reasonably clear day as can be seen from the $\mathrm{O}_{4}$ measurements shown in Fig. 14) a cruising ship entered the fiord in the afternoon and stayed in the harbour of $\mathrm{Ny}$-Ålesund for a few hours from 18:00 LT on. The $\mathrm{NO}_{2}$ columns measured on that day are presented in Fig. 15 for two different scenarios: a clean air scenario with $30 \mathrm{ppt} \mathrm{NO}_{2}$ in the boundary layer and a polluted scenario with $3 \mathrm{ppb}$ $\mathrm{NO}_{2}$. The clean air scenario leads to consistent results in the morning hours, but later in the day the different viewing directions yield different vertical columns, indicating that the assumed vertical profile is not appropriate. The polluted scenario on the other hand fails to bring the morning measurements together but leads to good agreement during the pollution peak in the late afternoon, indicating that at that time roughly $3 \mathrm{ppb}$ of $\mathrm{NO}_{2}$ were present in the boundary layer. The lowest viewing direction $\left(3^{\circ}\right)$ does not line up as nicely as the other directions. This might be due to some clouds very close to the horizon (see $\mathrm{O}_{4}$ from $3^{\circ}$ elevation angle between 18:00 and 20:00 UT in Fig. 14). Another reasonable explanation is a horizontal inhomogeneity in the $\mathrm{NO}_{2}$ field. In the model calculations, the absorber concentrations can only vary with height, and any horizontal gradient will introduce differences between model and measurements. As the horizontal path through the boundary layer is of the order of $20 \mathrm{~km}$ for the lowest viewing direction, a change in $\mathrm{NO}_{2}$ concentration along this light path is not unrealistic, in particular as the source is very localised. 


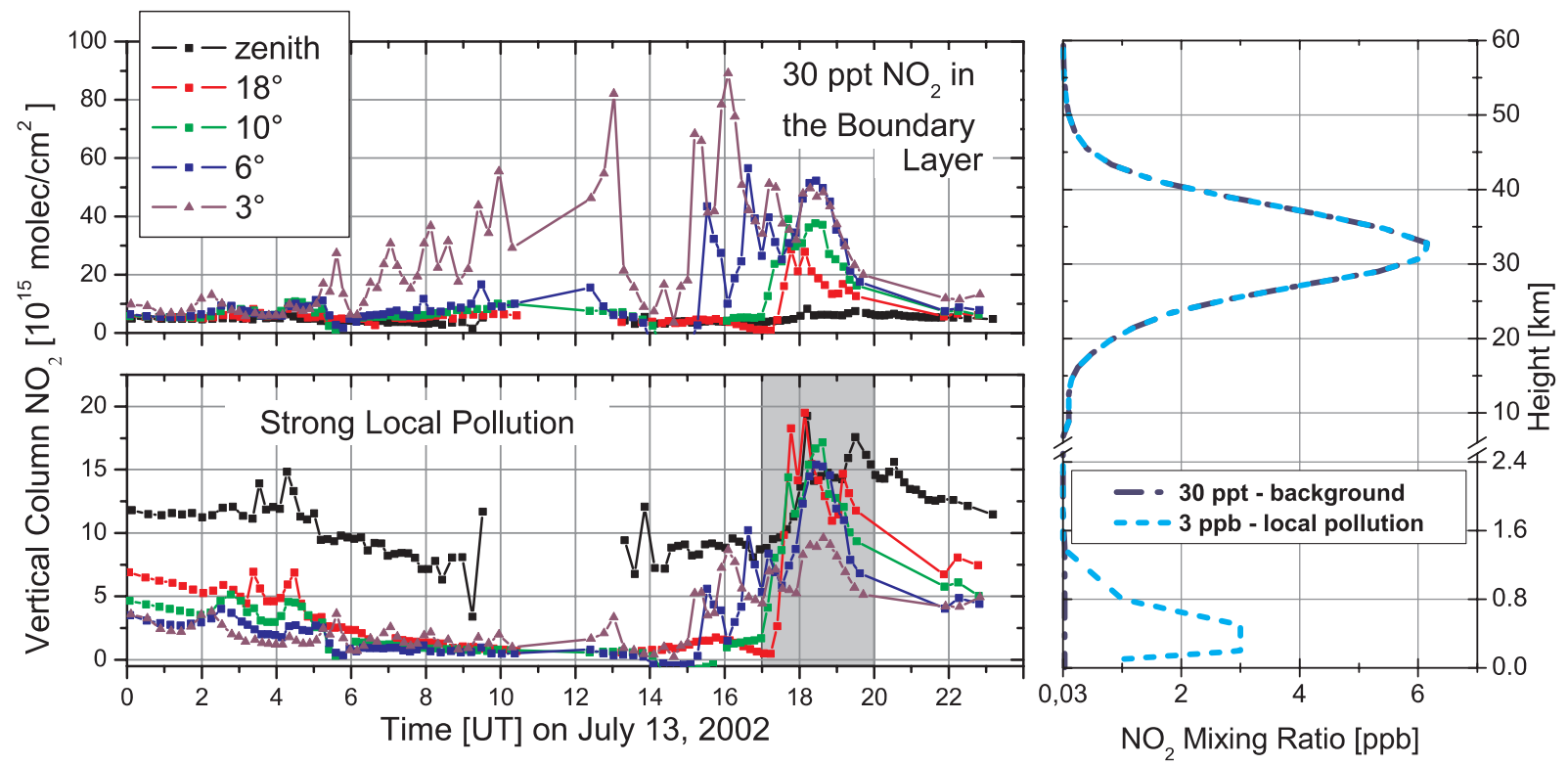

Fig. 15. $\mathrm{NO}_{2}$ vertical columns on 13 July 2003 calculated for all off-axis directions with two different scenarios. Between 17:00 and 20:00 UT strong local pollution with $3 \mathrm{ppb}$ in a layer close to the surface can be detected. Before 05:00 UT only $30 \mathrm{ppt}$ in the boundary layer have been detected. This value is a typical background volume mixing ratio of $\mathrm{NO}_{2}$ around $\mathrm{Ny}$-Ålesund.

\section{Conclusions}

A novel multi-axis UV/visible instrument (MAX-DOAS) has been described, that measures not only in the zenith direction, but also at several lines of sight close to the horizon. The instrument is operating in Ny-Ålesund in a 2 direction viewing mode since 1999 and with 5 viewing directions since March 2002.

Combination of the different viewing directions provides information on both tropospheric and stratospheric absorbers, and under clear sky conditions, some vertical profile information can be derived in the troposphere. To study the sensitivity of the measurements towards a number of parameters (multiple scattering, refraction, relative azimuth, surface albedo, and aerosols) model studies have been performed simulating the airmass factor for the oxygen dimer $\mathrm{O}_{4}$ with the radiative transfer model SCIATRAN. The main results are that multiple scattering has an important impact on the results whereas refraction is only of minor importance. The relative azimuth between viewing direction and solar position is a relevant parameter and has to be considered in any airmass factor calculation. In particular when the instrument is pointing towards the sun, the sensitivity of the measurements is decreased and large relative changes in $\boldsymbol{A M F}$ are observed. Therefore, instruments should be pointed away from the sun where possible. Surface albedo and aerosols both play an important role. Increasing albedo reduces the sensitivity for absorption in the lowest layers as does increasing aerosol extinction. For quantitative studies, both parameters need to be well known from external information or by retrieving them from $\mathrm{O}_{4}$ measurements.
The modeled $\boldsymbol{A M} \boldsymbol{F}$ have been applied to measurements of $\mathrm{O}_{4}$, and good agreement could be achieved between the results from different viewing directions. This is a crucial test of the ability to model the radiative transfer for this viewing geometry, and a prerequisite for application to other trace species.

As a sample application, one day of measurements in July 2002 have been analysed for $\mathrm{NO}_{2}$. In the morning of that day, clean background conditions prevailed and the analysis assuming $30 \mathrm{ppt}$ of $\mathrm{NO}_{2}$ in the boundary layer yields consistent results for all viewing directions. In the afternoon, $\mathrm{NO}_{2}$ columns observed with the lower viewing directions increased very much, and mixing ratios of up to $3 \mathrm{ppb}$ in the boundary layer were retrieved from the data. The high $\mathrm{NO}_{2}$ episode coincides with the visit of a cruise ship in the harbour of $\mathrm{Ny}-\AA ̊ \AA l e s u n d$, and $\mathrm{NO}_{\mathrm{x}}$ emissions from this ship are the most probable source of the observed plume.

In summary, Multi-Axis DOAS measurements are a promising tool for automated continuous measurements of several tropospheric species such as $\mathrm{NO}_{2}, \mathrm{BrO}, \mathrm{SO}_{2}, \mathrm{HCHO}$, and $\mathrm{O}_{3}$ (e.g. Heckel et. al., 2004; Hönninger and Platt, 2002). Quantitative analysis of the measurements depends on a number of parameters in the radiative transfer, and models such as SCIATRAN are now in a position to include all these factors with the necessary accuracy.

Acknowledgements. We wish to thank the Alfred-Wegener-Institute for Polar Research in particular the NDSC station engineers, without whom this study would not have been possible. We kindly acknowledge A. Herber from the Alfred-Wegener-Institute for 
providing aerosol data and P. von der Gathen for the sonde data. Parts of this work have been funded by the University of Bremen, the European Union under contract EVK2-CT2000-00059 (QUILT) and the German ministry for Science and Education (BMBF).

Edited by: A. Hofzumahaus

\section{References}

Bobrowski, N., Hönninger, G., Galle, B., and Platt, U.: Detection of bromine monoxide in a volcanic plume, Nature, 423, 273-276, 2003.

Frieß, U., Wagner, T., Pundt, I., Pfeilsticker, K., and Platt, U.: Spectroscopic measurements of tropospheric Iodine oxide at Neumayer station, Antarctica, Geophys. Res. Lett., 28, 1941-1944, 2001.

Greenblatt, G. D., Orlando, J. J., Burkholder, J. B., and Ravishankara, A. R.: Absorption measurements of oxygen between 330 and 1140 nm, J. Geophys. Res., D95, 18 577-18 582, 1990.

Heckel, A., Richter, A., Tarsu, T., Wittrock, F., Hak, C., Pundt, I., Junkermann, W., and Burrows, J. P.: MAX-DOAS measurements of formaldehyde in the Po-Valley, Atmos. Chem. Phys. Discuss., 4, 1151-1180, 2004.

Hönninger G. and Platt U.: The Role of BrO and its Vertical Distribution during Surface Ozone Depletion at Alert, Atmos. Environ., 36, 2481-2489, 2002.

Johnston, P. V., and McKenzie, R. L.: $\mathrm{NO}_{2}$ observations at $45^{\circ} \mathrm{S}$ during the decreasing phase of solar cycle 21, from 1980 to 1987 , J. Geophys. Res., D94, 3473-348, 1989.

Lawrence, M. and Crutzen, P.: Influence of $\mathrm{NO}_{\mathrm{x}}$ emissions from ships on tropospheric photochemistry, Nature, 402, 167-170, 1999.

Leser, H., Hönninger, G., and Platt, U.: MAX-DOAS measurements of $\mathrm{BrO}$ and $\mathrm{NO}_{2}$ in the marine boundary layer, Geophys. Res. Lett., 30, 10, doi:10.1029/2002GL015811, 2003.

Miller, H. L., Weaver, A., Sanders, R. W., Arpag, K., and Solomon, S.: Measurements of Arctic sunrise surface ozone depletion events at Kangerlussuaq, Greenland $\left(67^{\circ} \mathrm{N}, 51^{\circ} \mathrm{W}\right)$, Tellus, 49B, 496-509, 1997.

Noxon, J. F., Nitrogen dioxide in the stratosphere and troposphere measured by ground-based absorption spectroscopy, Science, 189, 547-549, 1975.

Noxon, J. F., Norton, R. B., and Henderson, W. R.: Observation of atmospheric $\mathrm{NO}_{3}$, Geophys. Res. Lett., 5, 675-678, 1978.

Oriel: The Book of Photon Tools, distributed by Oriel Corporation, available through the World Wide Web at http://www.oriel.com, 2001.

Perliski, L. M. and Solomon, S.: On the evaluation of air mass factors for atmospheric near-ultraviolet and visible absorption spectroscopy, J. Geophys. Res., 98, D6, 10363-10 374, 1993.

Perner, D., and Platt, U.: Absorption of light in the atmosphere by collision pairs of oxygen $\left(\mathrm{O}_{2}\right)_{2}$, Geophys. Res. Lett., 7, 1053105, 1980.
Platt, U.: Differential optical absorption spectroscopy (DOAS), in Air Monitoring by Spectroscopic Techniques, Chem. Anal. Ser., edited by Sigrist, M. W., 127, 27-84, John Wiley, New York, 1994.

Richter, A., Eisinger, M., Ladstätter-Weißenmayer, A., and Burrows, J. P.: DOAS zenith sky observations. 2. Seasonal variation of BrO over Bremen (53 N) 1994-1995, J. Atm. Chem., 32, 8399, 1999.

Rozanov, A., Rozanov, V. V., and Burrows, J. P.: Combined differential-integral approach for the radiation field computation in a spherical shell atmosphere: Nonlimb geometry, J. Geophys. Res., 105, D18, 22,937, 2000.

Rozanov, A., Rozanov, V. V., and Burrows, J. P.: A numerical radiative transfer model for a spherical planetary atmosphere: combined differential-integral approach involving the Picard iterative approximation, Journal of Quantitative Spectroscopy and Radiative Transfer, 69, 491, 2001.

Sanders, R. W., Solomon, S., Caroll, M. A., Smith, J. P., Perliski, L., Miller, H. L., Mount, G. H., Keys, J. G., and Schmeltekopf, A. L.: Visible and near-ultraviolet spectroscopy at McMurdo Station, Antarctica, 9: Observation of OClO from April to October 1991, J. Geophys. Res., 98, D1, 7219-7228, 1993.

Solomon, S., Schmeltekopf, A. L., and Sanders, R. W.: On the interpretation of zenith sky measurements, J. Geophys. Res., 92, D7, 8311-8319, 1987.

Tørnkvist, K. K., Arlander, D. W., and Sinnhuber, B.-M.: GroundBased UV Measurements of $\mathrm{BrO}$ and $\mathrm{OClO}$ over $\mathrm{Ny}$-Ålesund during Winter 1996 and 1997 and Andøya during Winter 1998/1999, J. Atm. Chem., 43, 75-106, 2002.

Van de Hulst, H., Light Scattering by Small Particles, Dover Publications Inc., 180 Varick Street, New York, N.Y. 10014, 1981.

Van Roozendael, M., Hermans, C., DeMaziere, M., and Simon, P. C.: Stratospheric $\mathrm{NO}_{2}$ observations at the Jungfraujoch Station between June 1990 and May 1992, Geophys. Res. Lett., 21, 1383-1386, 1994.

Van Roozendael, M., Fayt, C., Post, P., Hermans, C., Lambert, J.C.: Retrieval of $\mathrm{BrO}$ and $\mathrm{NO}_{2}$ from UV-Visible Observations, in: Sounding the troposphere from space: a new era for atmospheric chemistry, Springer-Verlag, ISBN 3-540-40873-8, edited by Borell, P. et al., 2003.

Vountas, M., Rozanov, V. V., and Burrows, J. P.: Impact of Raman Scattering on Radiative Transfer in Earth's atmosphere, J. Quant. Spectrosc. Radiat. Transfer, 60, 6, 943-961, 1998.

Wagner, T., von Friedeburg, C., Wenig, M., Otten, C., and Platt, U.: $\mathrm{UV} /$ vis observations of atmospheric $\mathrm{O}_{4}$ absorptions using direct moon light and zenith scattered sunlight under clear and cloudy sky conditions, J. Geophys. Res., 107, D20, 4424, 2002.

Wittrock, F., Müller, R., Richter, A., Bovensmann, H., and Burrows, J. P.: Observations of Iodine monoxide above Spitsbergen, Geoph. Res. Let., 27, 10, 1471-1474, 2000. 